\title{
Subhasish M. Chowdhury* Conflict in the Time of (Post-) Corona: Some Assessments from Behavioral Economics
}

https://doi.org/10.1515/peps-2020-0052

Received August 9, 2020; accepted August 11, 2020

Abstract: We present a non-technical assessment of the effects of the COVID-19 pandemic on individual level conflict behavior in the household, workplace, and societal interactions in the post-COVID era. We predict that there will be an increase in the intra-household conflict including domestic violence; and the divorce rate will rise. Within workplaces, the pandemic will result both in a higher level of sabotage among the employees, and employee retaliation towards the employer. The pandemic may also affect the diversity and inclusiveness within an organization adversely. In societal interactions, an increase in the identity related conflicts - especially related to the immigration status can be observed. It is also likely that there will be an increase in the attack and defense or victimization activities in the society. We conclude by proposing various measures for conflict resolution, and a few possible areas of further investigations.

Keywords: conflict, COVID-19 pandemic, behavioral economics

JEL Classification: C72, D74, D91

I thank two anonymous referees, Raul Caruso and Joo Young Jeon for comments. Any remaining errors are my own.

*Corresponding author: Subhasish M. Chowdhury, Department of Economics, University of Bath, BA2 7AY Bath, UK, E-mail: s.m.chowdhury@bath.ac.uk. https://orcid.org/0000-0002-8386-9144 
"Everybody knows that pestilences have a way of recurring in the world, yet somehow we find it hard to believe in ones that crash down on our heads from a blue sky. There have been as many plagues as wars in history, yet always plagues and wars take people equally by surprise."

-Albert Camus (The Plague, 1947).

\section{Introduction}

Conflict and conflict resolution are integral parts of our life. While people often link the concept of 'conflict' to war, civil unrest, terrorism etc., the broad idea of conflict also includes conflict at the micro (individual) level. This type of conflict includes dispute within a household, clash within an organization, fight between individuals-to name a few. There has been a plethora of studies to understand and mitigate conflict in such individual level. However, a life changing historical event such as the coronavirus disease 2019 (COVID-19) pandemic should have significant effects on such individual level conflict behavior as well. This study aims to provide a non-technical assessment of such changes through the lenses of behavioral economics.

To do so, however, one is required to put it in the relevant context. The COVID19 pandemic has a deep and long lasting implication. ${ }^{1}$ Since its appearance in December 2019 until the middle of August 2020, the virus has already infected about 20 million people with a death toll of about 750 thousand people worldwide. Furthermore, the fear of infection and government imposed lockdown has taken a toll in the global economy. Fernandes (2020), for example, forecasts a GDP growth rate of up to $-10 \%$ for a sample of 30 countries, while for some countries it is predicted to be worse than $-15 \%$. Hence, it is important to predict the micro effects contingent upon the situations that the economy and the society will ultimately face. We, thus, make two (optimistic) assumptions. First, the pandemic will be over in the near future either due to the invention of vaccines; or due to achieving herd immunity. If that is not the case, then it will not make sense to predict human behavior in a post-COVID era. Second, in the longer term after the pandemic is over, the economy and the society will return (close to) the pre-pandemic situation. Hence, the viewpoints here will cover the time frame between the end of the pandemic and the return of 'normalcy'.

1 See Chakraborty and Maity (2020) for the background of the COVID-19 pandemic, and its generic effects. 
There are various ways one can cover and analyze situations in which individuals are engaged in micro level conflict. Hence, one is required to pre-set the scope of the study. We aim to provide predictions based upon the existing literature of conflict and related field in Economics and in Psychology. Moreover, a branch of game theory that is applied to analyze such micro-conflict behavior in organizations, in which individuals expend costly resources to win over some valuables (e.g., money, status, position), is called 'contest theory'. Since some situations of interest match with this structure, a part of the current study will use the knowledge obtained from the behavioral research on contest theory to predict post-COVID conflict behavior.

In the continuation we discuss the effects of COVID-19 on individual conflict behavior at home (Section 2), at workplace (Section 3), and at the broader society (Section 4). Section 5 concludes.

\section{Effects on the Household: Domestic Violence and Divorce}

The loss of near ones, health, job, income, related stress and mental health issues due to the pandemic will take its toll on household and family lives. The COVID-19 pandemic has a tremendous damaging effect in income and employment that will influence the household (conflict) behavior. This effect arises both due to the government imposed lockdown, and the lack of business, shortage of inputs etc. even without a lockdown. Alas, Canal, and Hunt (2020), in their study for McKinsey, estimate that around 7.6 million (24\% of the national labor force) jobs only in the United Kingdom are at risk due to the pandemic. All these broader economic downturns result in a lower income and even loss of employment at a household level. Moreover, the pandemic resulted in health concerns, death of near ones, and "problems such as stress, anxiety, depressive symptoms, insomnia, denial, anger and fear" around the world (Torales et al. 2020).

It has been documented that negative emotions result in lower cooperation (Drouvelis and Grosskopf 2016) and higher conflict behavior (Nair 2008). Since the COVID-19 pandemic resulted in mental health issues and negative emotions, one can predict a higher level of conflict within the household due to the pandemic. Combining this with a possible lower level of cooperation between the household members may ignite even further conflict. Indeed, Taub (2020) reports a worldwide rise in domestic violence during the COVID-19 pandemic. Furthermore, Alon et al. (2020) predict that the employment situation for females will be significantly worse than their male counterparts in an immediate post-COVID era. In sum, these 
portray a rather grim picture. If the economic and employment recovery in the postCOIVD era is not fast enough, these issues of mental health and negative emotions may have a long lasting effect and one will expect a higher rate of domestic conflict and violence even in the post-COVID time. However, given the unequal job opportunities the females will face, they are more likely to be victims of such domestic violence on an even higher rate.

Domestic violence and other forms of physical conflict are not the only types of conflict a household member faces. Mental and psychological conflict often referred to be a prominent reason for discord within a family. A long lasting effect of COVID-19 may be in this aspect as well. It has already been observed in China that divorce rates were higher due to the COVID-19 pandemic and related lockdown (Landsverk 2020). This is unsurprising because a spike in the divorce rate in January is often attributed to the mental and financial stress at the festive time, and extended interaction between the couple at that time. One would expect spillover of such effects even at the post-COVID time resulting in a higher level of conflict and divorce in the households.

\section{Effects on the Workplace: Sabotage and Employee Retaliation}

One of the highest affected area in terms of individual conflict in the aftermath of the COVID-19 pandemic will be the workplace. Employees across industries compete with their colleagues either directly in terms of bonus, promotion etc., or indirectly in terms of status, peer recognition etc. (see, e.g., Lazear and Rosen 1981) and spend efforts to secure a higher relative position in those competitions. Whereas a certain level of stress may indeed improve the competition and production in an organization, an excessive level of stress (due to the pandemic, as discussed) may damage it. At the same time, a contracted economy and lesser demand due to the pandemic will eventually have an effect on the compensation structure. A damaged compensation structure will then affect the effort provision and other behaviors of the employees, further impairing the organization.

We predict two prominent types of conflict to be emerging in the workplace due to the COVID-19 pandemic. First, to show a better relative performance compared to the peers, some employees may resort to sabotaging their peers instead of concentrating on their own duties. Sabotage refers to the harmful acts such as withholding crucial information from colleagues, spoiling other's work, 
spreading malicious rumors in the workplace etc. ${ }^{2}$ This type of conflict is aimed to damage the performance of the competitor and gain relative benefits for oneself. Second, employees may be inclined to engage in 'employee retaliation' towards the employer or the management by resorting to 'go slow' (expend less effort), damage organization properties and reputation etc. This act of conflict arises not necessarily to reap their own benefit, but due to their social preference (getting even to the society or to the organization). Below I discuss these in detail.

Sabotage may occur for various reasons. But when the individual employees are more willing to win the prized relative position, it is more likely to happen. Due to the COVID-19 pandemic and the related economic recession, every bonus, promotion, and relative recognition will be understandably valued much higher by the individual employees-prompting them to opt for such sabotage acts. Moreover, a 'perform or else' policy in the organization will prompt loss aversion (Kahneman, Knetsch, and Thaler 1991) to the employees towards their job or compensation. Such loss aversion also increases conflict among the employees (Chowdhury, Jeon, and Ramalingam 2018). If not prohibited, then this can result in a dire situation, in which not only the employees damage each other's work, but they also learn from each other how to implement such damaging acts on others. Furthermore, it is possible that an employee, who is a victim of a sabotage act, seeks for revenge; and an endless loop of sabotage may prevail in the organization (Bolle, Tan, and Zizzo 2014).

The act of employee retaliation emerges from a different emotional background than simple career related benefits. Employees engage in such conflictive behavior when they feel that they are treated inappropriately or unjustly. As discussed, a practical outcome of the pandemic will be a series of job loss and possible pay cuts. This will obviously trigger an employee retaliation that can range from intentional delay in work to an organized strike. The employees may also get triggered and engage in such employee retaliation acts if they observe financial support by the government to the organizations, but no improvement in their own situations.

Sabotage behavior as a consequence of the COVID-19 pandemic can have a long lasting effect on diversity and affirmative action (Chowdhury, Esteve-González, and Mukherjee 2020) as well. It has been documented that affirmative action attracts higher level of sabotage (Brown and Chowdhury 2017). Hence, it is possible that in the post-COVID situation, an affirmative action policy increases the conflict in terms of sabotage activities. Moreover, experimental results (Leibbrandt, Wang, and Foo 2018) show that with such affirmative action policies females are targeted

2 For further examples and a detailed survey on the reasons for sabotage, tools of sabotage, and the mechanisms to deter sabotage see Chowdhury and Gürtler (2015). 
more with sabotage. Hence, overall this will affect the career progression and performance of females in a disproportionate way. Implementation of affirmative action, unfortunately, has similar negative effects in terms of employee retaliation (Fallucchi and Quercia 2018) as well. In summary, an employer will have to be very careful in the post-COVID era while implementing affirmative action policies for both sabotage and employee retaliation reasons.

A further possibility of conflict in the organizations may arise while working in a team-setting in which all the team members reap the benefits of the team success. Working in such a team requires both coordination and cooperation of efforts among the team members. However, as discussed earlier, the stress and cognitive load incurred due to the COVID-19 pandemic can make some individuals not to coordinate or contribute for the team (Goeschl and Lohse 2018). This means they simply free-ride on their team-mates' efforts. In such a situation, the hardworking team members may feel frustrated and try to punish the free-riders-initiating a conflict. However, the free-riders may also try to punish the hardworking ones since the hard-workers make the free-riders look bad within the team (Herrmann, Thöni, and Gächter 2008). Such infighting and conflict severely damage the likelihood of a team success. Hence, it will be a challenging situation for the management while managing teams and team based projects in the post-COVID era.

\section{Effects on Societal Interactions: Identity, Immigration, Attack and Defense}

There is life beyond home and workplace and, unfortunately, the COVID-19 pandemic may affect people's conflict behavior in such social interactions as well. As discussed earlier, the COVID-19 pandemic brought us into a global recession, and a recession may increase the internal conflicts in a country (Blomberg and Hess 2002). Here we discuss the possible areas where such conflict at an individual level can be observed.

A very important dimension of societal conflict centers around the concept of 'identity'. One's identity is their sense of self-what they perceive themselves to be, as well as what they perceive other people to be. Some examples of such identity are one's race, religion, language, nationality, immigration status, economic class etc. Sen (2007) suggests that each individual has multi-dimensional identities. Yet, when a particular dimension becomes salient, then it instigates and intensifies conflict. Chowdhury, Jeon, and Ramalingam (2016) find empirical support for this hypothesis from a laboratory experiment. Historically, a recession intensifies the concept of identity and makes inequality between the majority and minority 
greater (Charles 2011). One can already note various identity related conflicts (race in the USA, religion in India etc.) being intensified around the world during the pandemic. We predict this trend to be continued in the post-COVID era as well.

Along with race and religion, one of the most prolific identity engaged in conflict in recent years has been the immigration status. The Economist (2020) notes that the post-COVID time will be marred with less immigration and reduced immigrant population around the world; and the most affected immigrant population would be the ones engaged in blue collar jobs. For example, due to the pandemic about half a million blue collar Indian immigrants in the United Arab Emirates have registered to be evacuated and a significant proportion of them have already returned to India. While such exodus will affect the global economy itself, it will make the immigrants a further minority in their host countries. In the recession time of the post-COVID era under populist regimes one would expect such minorities to be victimized and attacked.

This also brings in another type of conflict in which there is an attacker and a defender (Chowdhury 2019). Till now we have implicitly concentrated on situations in which the engaged parties are equally positioned. However, there are very many situations (e.g., refugees located close to antagonized natives, or oppressed minority in an authoritarian state) in which the minorities only defend and a part of the majority attack. ${ }^{3}$ Given the economic impact on the economy, a significant proportion of the low income immigrants will have to leave their host countries (The Economist 2020), but the higher income earning immigrants will stay back. This will show a relatively higher average income of the immigrants compared to the natives. As shown in Mitra and Ray (2014), albeit in the context of religious identity in India, such situation will trigger the majority to victimize and attack the minority (immigrants in the current context).

\section{Discussion}

We aim to provide an assessment of the individual conflicts in the post-COVID era. In summary, we expect a higher level of both physical and non-physical conflict within a household. Some of such conflicts may result in domestic violence mostly towards females, and in divorce. Note, however, that the rate of each of these may vary from country to country as well as society to society. Whereas one may expect

3 Although similar, attack and defense should not be confused with 'crime'. In crime the engaged parties also are not equally positioned; there is one initiator (the criminal) and a victim. The COVID-19 generated recession can increase the conventional crimes of the powerless as well as unconventional white collar crimes of the powerful (Box 1987). However, crime is not categorized as conflict and is out of scope of this study. 
a higher divorce rate even with a relatively lower rate of domestic violence in a higher income society, it may be the opposite in a lower income one. In the workplace, the post-COVID situation may show a lower level of cooperation and a higher level of sabotage towards peers. One should also expect a spike in employee retaliation against the organization or the management at this time. Both of these will have a negative impact on diversity. Conflict among peers in group projects may also intensify. In the societal interaction as well, we predict a higher level of identity related conflict. There may be victimization and attacks on immigrants.

These predictions, however, will have to be considered with caution. While we point out the areas where individual conflict may increase, we do not aim to predict the level of such conflicts. This is because the levels depend on very many other factors such as initial economic condition, relationship between various identity groups, culture, political regime, organizational structure etc. What may be more important is to point out possible mechanisms to deter and mitigate such conflicts. For household level conflict, further support to the domestic violence victims, and counselling for the conflictive parties will be of help. Within an organization both sabotage and employee retaliation can be reduced by increasing the cost of such act, as well as creating a more absolute (instead of relative) performance driven environment. Allowing positive emotions in the organization may also mitigate some of the conflictive situations. In the broader society, the authorities can actively make common identities (e.g., common 'nationality' among various religious groups in India) salient to reduce identity related conflicts. It has been observed that mediation and communication mitigate conflict. Hence, both for immigration and for attack and defense situations such acts will also help.

We conclude by highlighting some possible interesting areas of research in individual conflict that can be arranged in the post-COVID era. Although a recession reduces global income and that can cause a higher level of conflict, it also reduces people's resources to be spent on conflict. Chowdhury and Moffatt (2017) and Baik, Chowdhury, and Ramalingam (2020) show that the availability of the conflict budget and the level of conflict has an inverted-U shaped relationship. Hence, it may be possible that when people with medium conflict budget hit with a COVID related recession, they end up with a low conflict budget and as a result engage less in conflict. For the people with initial high conflict budget this may have the opposite effect. Both empirical and experimental investigation of such effects will be interesting to observe. It will also be interesting to tease out the effects of economic versus psychological effects of the pandemic on conflict behavior. Furthermore, De Dreu et al. (2019) show that people with higher social concerns and higher empathy engage less in conflict, whereas Chowdhury (2019) show that a higher spitefulness increases conflict. One may be able to use the tools of economics and neuro science experiments to understand the effects of COVID-19 
pandemic on such emotions and social preferences. It will also be important to replicate existing behavioral economics, psychology and neuro science results of conflict behavior on the post-COVID population.

\section{References}

Alas, T., M. Canal, and V. Hunt. 2020. COVID-19 in the United Kingdom: Assessing Jobs at Risk and the Impact on People and Places. McKinsey and Company Article, 11 May. Also available at https://www.mckinsey.com/industries/public-and-social-sector/our-insights/covid-19-inthe-united-kingdom-assessing-jobs-at-risk-and-the-impact-on-people-and-places.

Alon, T., M. Doepke, J. Olmstead-Rumsey, and M. Tertilt. 2020. "The Impact of the Coronavirus Pandemic on Gender Equality." Covid Economics Vetted and Real-Time Papers, (4). https:// doi.org/10.3386/w26947.

Baik, K. H., S. M. Chowdhury, and A. Ramalingam. 2020. "The Effects of Conflict Budget on the Intensity of Conflict: An Experimental Investigation.” Experimental Economics 23 (1): 240-58.

Blomberg, S. B., and G. D. Hess. 2002. "The Temporal Links Between Conflict and Economic Activity." Journal of Conflict Resolution 46 (1): 74-90.

Bolle, F., J. H. Tan, and D. J. Zizzo. 2014. "Vendettas." American Economic Journal: Microeconomics 6 (2): 93-130.

Box, S. 1987. Recession, Crime and Punishment. London: Macmillan International Higher Education.

Brown, A., and S. M. Chowdhury. 2017. "The Hidden Perils of Affirmative Action: Sabotage in Handicap Contests.” Journal of Economic Behavior \& Organization 133: 273-84.

Chakraborty, I., and P. Maity. 2020. "COVID-19 Outbreak: Migration, Effects on Society, Global Environment and Prevention." Science of the Total Environment 728: 138882.

Charles, A. 2011. "The Great Recession and Ethnic Inequality in the US Labour Force." History of Economic Ideas 19: 163-76.

Chowdhury, S. M. 2019. "The Attack and Defense Mechanisms-Perspectives From Behavioral Economics and Game Theory." Behavioral and Brain Sciences 42: e121.

Chowdhury, S. M., P. Esteve-González, and A. Mukherjee. 2020. Heterogeneity, Leveling the Playing Field, and Affirmative Action in Contests. SSRN Working Paper No. 3655727. Also available at https://papers.ssrn.com/sol3/papers.cfm?abstract_id=3655727.

Chowdhury, S. M., and O. Gürtler. 2015. “Sabotage in Contests: A Survey.” Public Choice 164 (1-2): 135-55.

Chowdhury, S. M., J. Y. Jeon, and A. Ramalingam. 2016. "Identity and Group Conflict.” European Economic Review 90: 107-21.

Chowdhury, S. M., J. Y. Jeon, and A. Ramalingam. 2018. "Property Rights and Loss Aversion in Contests." Economic Inquiry 56 (3): 1492-511.

Chowdhury, S. M., and P. G. Moffatt. 2017. "Overbidding and Heterogeneous Behavior in Contest Experiments: A Comment on the Endowment Effect." Journal of Economic Surveys 31 (2): 572-6.

De Dreu, C. K., M. Giacomantonio, M. R. Giffin, and G. Vecchiato. 2019. "Psychological Constraints on Aggressive Predation in Economic Contests." Journal of Experimental Psychology: General 148 (10): 1767-81. 
Drouvelis, M., and B. Grosskopf. 2016. "The Effects of Induced Emotions on Pro-Social Behaviour." Journal of Public Economics 134: 1-8.

Fallucchi, F., and S. Quercia. 2018. "Affirmative Action and Retaliation in Experimental Contests." Journal of Economic Behavior \& Organization 156: 23-40.

Fernandes, N. 2020. Economic Effects of Coronavirus Outbreak (COVID-19) on the World Economy. Also available at https://doi.org/10.2139/ssrn.3557504.

Goeschl, T., and J. Lohse. 2018. "Cooperation in Public Good Games. Calculated or Confused?" European Economic Review 107: 185-203.

Herrmann, B., C. Thöni, and S. Gächter. 2008. “Antisocial Punishment Across Societies.” Science 319 (5868): 1362-7.

Kahneman, D., J. L. Knetsch, and R. H. Thaler. 1991. "Anomalies: The Endowment Effect, Loss Aversion, and Status Quo Bias.” The Journal of Economic Perspectives 5 (1): 193-206.

Landsverk, G. 2020. The Coronavirus May Be Driving up Divorce Rates in a Chinese City, Officials Say. Business Insider. Also available at https://www.businessinsider.com/covid-19-peakdivorce-rate-chinese-cities-2020-3.

Lazear, E. P., and S. Rosen. 1981. “Rank-Order Tournaments as Optimum Labor Contracts.” Journal of Political Economy 89 (5): 841-64.

Leibbrandt, A., L. C. Wang, and C. Foo. 2018. "Gender Quotas, Competitions, and Peer Review: Experimental Evidence on the Backlash Against Women.” Management Science 64 (8): 3501-16.

Mitra, A., and D. Ray. 2014. "Implications of an Economic Theory of Conflict: Hindu-Muslim Violence in India." Journal of Political Economy 122 (4): 719-65.

Nair, N. 2008. "Towards Understanding the Role of Emotions in Conflict: A Review and Future Directions." International Journal of Conflict Management 19 (4): 359-81.

Sen, A. 2007. Identity and Violence: The Illusion of Destiny. New Delhi: Penguin Books India.

Taub, A. 2020. A New Covid-19 Crisis: Domestic Abuse Rises Worldwide. In The New York Times, 6 April. Also available at https://www.nytimes.com/2020/04/06/world/coronavirusdomestic-violence.html.

The Economist. 2020. Tearing Up the Welcome Mat. 01 August. Also available at https://www. economist.com/international/2020/08/01/when-covid-19-recedes-will-global-migrationstart-again.

Torales, J., M. O'Higgins, J. M. Castaldelli-Maia, and A. Ventriglio. 2020. "The Outbreak of COVID19 Coronavirus and Its Impact on Global Mental Health." International Journal of Social Psychiatry 66: 317-20. 